\title{
Development of an intervention to reduce antibiotic use for childhood coughs in UK primary care using critical synthesis of multi-method research
}

Patricia J. Lucas ${ }^{1 *}$, Jenny Ingram ${ }^{2}$, Niamh M. Redmond ${ }^{3,4}$, Christie Cabral ${ }^{4}$, Sophie L. Turnbull ${ }^{4}$ and Alastair D. Hay ${ }^{4}$

\begin{abstract}
Background: Overuse of antibiotics contributes to the global threat of antimicrobial resistance. Antibiotic stewardship interventions address this threat by reducing the use of antibiotics in occasions or doses unlikely to be effective. We aimed to develop an evidence-based, theory-informed, intervention to reduce antibiotic prescriptions in primary care for childhood respiratory tract infections (RTI). This paper describes our methods for doing so.

Methods: Green and Krueter's Precede/Proceed logic model was used as a framework to integrate findings from a programme of research including 5 systematic reviews, 3 qualitative studies, and 1 cohort study. The model was populated using a strength of evidence approach, and developed with input from stakeholders including clinicians and parents.

Results: The synthesis produced a series of evidence-based statements summarizing the quantitative and qualitative evidence for intervention elements most likely to result in changes in clinician behaviour. Current evidence suggests that interventions which reduce clinical uncertainty, reduce clinician/parent miscommunication, elicit parent concerns, make clear delayed or no-antibiotic recommendations, and provide clinicians with alternate treatment actions have the best chance of success. We designed a web-based within-consultation intervention to reduce clinician uncertainty and pressure to prescribe, designed to be used when children with RTI present to a prescribing clinician in primary care.

Conclusions: We provide a worked example of methods for the development of future complex interventions in primary care, where multiple factors act on multiple actors within a complex system. Our synthesis provided intervention guidance, recommendations for practice, and highlighted evidence gaps, but questions remain about how best to implement these recommendations. The funding structure which enabled a single team of researchers to work on a multi-method programme of related studies (NIHR Programme Grant scheme) was key in our success.
\end{abstract}

Trial registration: The feasibility study accompanying this intervention was prospectively registered with the ISRCTN registry (ISRCTN23547970), on 27 June 2014.

Keywords: Intervention development, Respiratory tract infections, Child, Drug resistance, Microbial, Models, Psychological, Primary health care, Mixed methods, Evidence synthesis

\footnotetext{
* Correspondence: Patricia.lucas@bristol.ac.uk

${ }^{1}$ School for Policy Studies, University of Bristol, 8 Priory Rd, Bristol, UK

Full list of author information is available at the end of the article
} 


\section{Background}

Antimicrobial resistance (AMR) is recognized as a global threat to human health, livelihoods and the economy [1-3]. Per annum 23,000 deaths in the USA, and 30,000 in the EU, are caused by treatment resistant bacteria [2]. In response to this threat, urgent policy action at national and international levels is needed including the development of AMR stewardships or responsible use strategies [2-5]. AMR stewardship encompasses strategies to ensure appropriate antimicrobial prescribing, including better targeting of treatment and reduced rates of prescription for self-limiting and non-bacterial infections $[2,6]$.

Current evidence suggests stewardship interventions in primary care can be effective in reducing antibiotic prescription and consumption rates [6, 7]. However, rigorous studies of carefully designed stewardship interventions, which recognize the complex multi-factorial social and behavioural influences on prescribing practice, monitor health impact, and include cost information are lacking [8]. The design of interventions targeting treatment of children is particularly challenging, given the multiple actors (clinician, child and parent) and behavioural triggers operating [9-13]. Childhood cough is the most common reason to attend primary care in the UK $[8,14]$, so identifying strategies to reducing antibiotics prescribed for respiratory tract infections (RTI) in childhood is important.

While guidance recommends an iterative approach to developing complex interventions [15], methods for achieving this are still emerging $[16,17]$ and intervention content and development are seldom presented in sufficient detail [18]. There is a need for greater clarity about the methods for designing interventions to change health professionals' behaviour in particular [19]. As part of a 5-year programme of research we undertook linked primary research and systematic reviews [20-32]. The final study in this programme was to develop and pilot an intervention, synthesising across the prior studies to produce intervention recommendations informed by both theory and research [33, 34]. The purpose of this paper is to describe the methods of synthesis and intervention development, present our recommendations for stewardship strategies for clinical and research audiences, and describe our intervention in sufficient detail to allow replication (Additional file 1 TIDieR checklist) [18]. A feasibility study exploring the acceptability of the intervention and feasibility of a future effectiveness study is published elsewhere $[35,36]$.

\section{Methods}

The Programme of research

This paper reports on one of five workstreams (WS) in the TARGET programme of research. The research was conducted between 2010 and 2016, with the aim of improving the management of children presenting to primary care with cough and RTIs. Figure 1 provides a schematic diagram of the programme, and illustrates the sequential, multi-method programme of research. The methods for individual studies are reported elsewhere, appropriate ethical review was gained for all elements [20-28, 31, 36, 37]. Parent and clinician advisory groups contributed to all stages of the research. This paper reports on the translation WS, which synthesised findings from WS1-3 and translated these into a model for a novel intervention to be tested in a feasibility study (WS4) [35, 36].

Our model was therefore informed by:

1. Systematic review (SR) and meta-analysis of randomised controlled trials (RCTs) to reduce antibiotic prescribing for childhood RTIs [20].

2. SR of RCTs to alter parents' consulting or antibiotic use when their children had an RTI [24].

3. SR with pooled symptoms estimates of observational studies charting the natural history of childhood RTIs [23].

4. SR and thematic synthesis of qualitative studies of the views, attitudes and experience of parents and clinicians about prescribing for minor childhood infections [38].

5. SR and meta-ethnography of observational qualitative studies of communication within consultations for acute childhood illness [25].

6. Interviews with parents exploring their experiences of consulting for childhood RTIs [39].

7. Focus groups and interviews establishing parents' information needs and self-efficacy beliefs in relation to coughs [40].

8. Interviews conducted with health professionals explored perceptions about their own prescribing decisions [31].

9. Critical synthesis of qualitative research generating a new theoretical understanding of safety seeking in childhood consultations [27].

10. Large cohort study (>8300 children) presenting with acute cough RTI into a prospective observational study tracking hospitalization for RTI illness and children's recovery in the 4 weeks following consultation providing a clinical prediction rule (CPR) for children at risk of hospitalization following RTI consultation [22, 32].

\section{Logic model selection}

We identified Greene and Kreuter's Precede/Proceed $[41,42]$ model as a vehicle for translating our findings into behavioural recommendations (Fig. 2). This model draws on social cognitive theories which hypothesize 


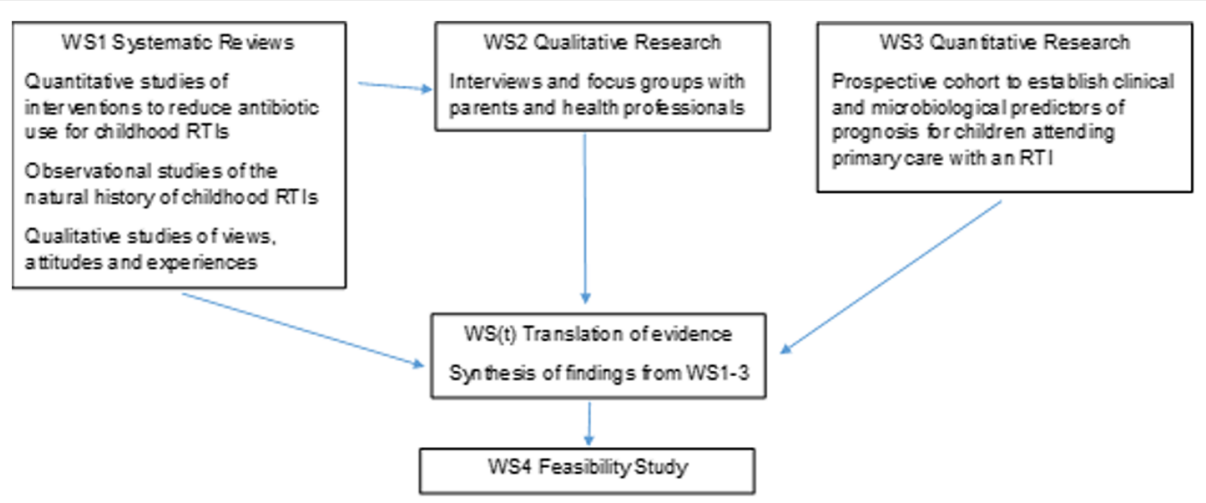

Fig. 1 TARGET Schema

that behaviour is influenced by context and by personal perceptions of costs, benefits and efficacy of actions [43-45]. Social cognitive theories are frequently used to understand health behaviours, including in the development of logic models informing behavioural interventions [46-54]. The Precede/Proceed approach integrates these elements into a unified model describing the interaction between the physical and social environment and individuals' motivations and intentions within a given health system [52]. Intervention planning (the 'precede' phase) is achieved by describing the circumstances under which a desired outcome comes about. The determinants of the outcome are divided into predisposing, enabling and reinforcing factors. Planning progresses to the 'proceed' phase by considering how change might be brought about and evaluated. This model has been used for health promotion and corresponding evaluations across a range of health topics, including understanding the use of antibiotics for minor child illness [55] and to synthesize qualitative and quantitative studies $[56,57]$.

Planning begins with defining the desired outcome, and we achieved this through discussion and consensus. The TARGET programme research team, parent and clinician advisory groups discussed potential outcomes of interest for policy makers, clinicians, parents and children. Outcomes considered included antibiotic prescription, antibiotic consumption, health experiences, and child health status. Our aim was to reduce antibiotic use without compromising health experience or status. In the UK, antibiotics cannot be accessed without a prescription from a qualified clinician, i.e. consumption is contingent upon prescription. We therefore chose antibiotic prescription as our target behaviour, and reduction in number of prescriptions to children with RTI as our primary outcome. We recorded hospitalisation for complication of RTI as an indicator of a poor health outcome.

\section{Synthesis of findings}

The behavioural target of this intervention was clinicians' prescribing decisions. As a team, we reviewed all the findings from the SRs and primary research conducted in TARGET to identify drivers of the decision to prescribe. The team of researchers responsible for each study element produced a summary of key findings which commented on contexts or behaviours which predisposed, reinforced, or enabled the antibiotic prescribing decision for children with a RTI presenting in

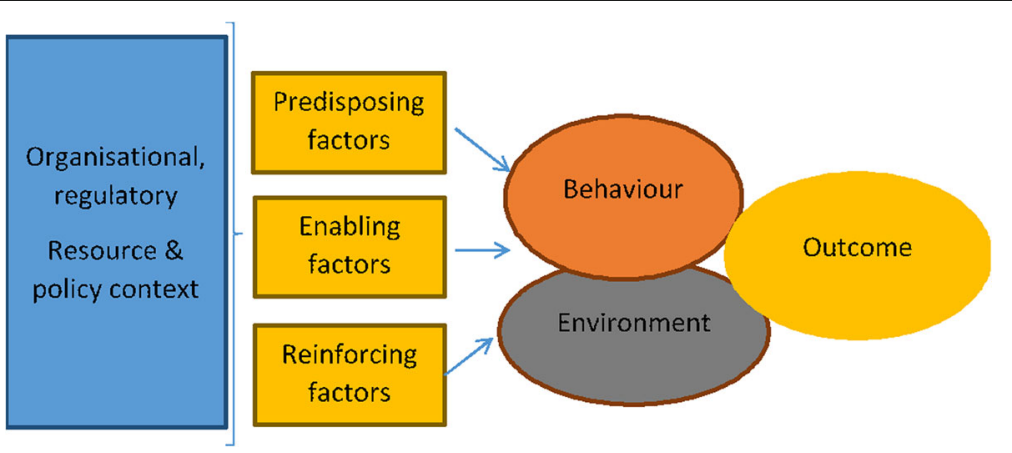

Fig. 2 Simplified model of change, adapted from Green \& Kreuter Precede/Proceed model of health promotion planning: http://lgreen.net/ precede.htm 
primary care. The synthesis team (PJL, JI, NR) assessed the weight of evidence for all factors identified. Where evidence was drawn from multiple sources we assigned a stronger evidence rating; for example, from several papers in systematic reviews, or from more than one study source. These evidence statements were presented to the full programme team and to the expert advisory group for discussion, comment and agreement.

\section{Intervention development and feasibility testing}

We used the evidence statements to develop intervention elements, in consultation with our programme team, programme steering committee, and parent and clinician advisory groups. A feasibility study established the acceptability and usability of our intervention $[35,36]$.

\section{Results}

The findings produced within the TARGET programme (including systematic reviews of existing evidence and primary research) provide the data for this study. The results of the evidence mapping and synthesis exercise are shown in Fig. 3, where we have mapped the evidence statements to the model components (Fig. 2). The number of ' + ' signs indicates the strength of evidence supporting each statement, where a single + indicates evidence from only one source, and three ' + 's evidence from multiple sources including systematic reviews. Citations to published findings are provided, but the synthesis included unpublished findings at the time.

Organisational and policy level changes (e.g. the introduction of prescribing guidelines, financial consequences, or changes to access to antibiotics) were not tested in the literature we reviewed but would be consistent with the model. In our discussion of the model we also predicted that making antibiotic prescriptions more visible to self and peers (ie systems for monitoring and peer sanctions) were plausible routes to discourage prescribing, but again these were not tested in the literature we reviewed and not mentioned by our participants.

\section{Intervention recommendations}

Evidence from past intervention studies clearly suggested that passive information for either parents or clinicians was unlikely to change antibiotic prescribing behaviour, but providing alternative treatment options probably would. Our analysis identified drivers of prescribing underexplored in the literature: the role of clinician uncertainty about diagnosis and prognosis, and the implications

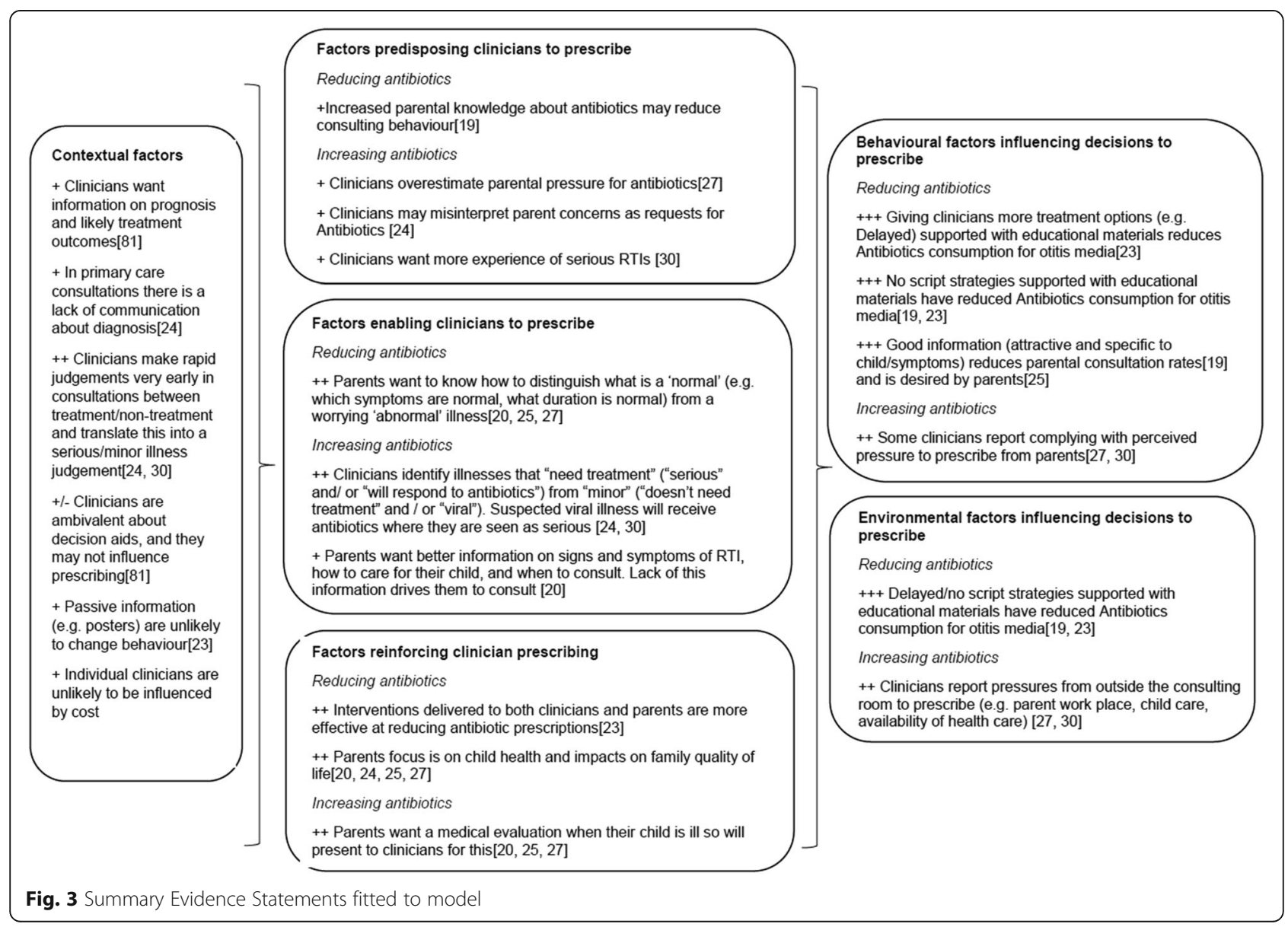


of miscommunications between parents and clinicians during consultation. The latter refers not to generic communication skills, but specific miscommunications about parents' desires and concerns, and clinicians' notreatment communications.

We used the evidence statements (Fig. 3) to develop a series of intervention recommendations describing the features of interventions delivered to individuals or groups considered most likely to be effective in changing antibiotic prescribing (Table 1, ordered from the strongest to the weakest evidence).

We argued that the intervention developed should aim to decrease clinical uncertainty about prognosis, provide clinicians with an action to support noantibiotic treatment strategies, and reduce miscommunication about parent concerns. Given the need to respond to consultation content (CPR and parent concerns) we chose to develop an interactive webbased intervention accessible from clinicians' desktops. While the intervention aims were evidencebased, we struggled to find literature to guide intervention design elements such as layout, look and personalisation of information. We worked with a graphic designer and web-development agency to ensure the intervention was attractive, easy to navigate, and personalized to each child. The intervention elements were tested with parents and clinicians using example materials and wireframes (showing the functional elements of the website). Wording was taken from NICE advice [58] supplemented with TARGET findings $[23,30]$ to ensure information provided was in line with best current evidence. We worked with a commercial web-design agency to develop the webbased tool, and a graphic designer to provide attractive images and a logo for our study (see Fig. 4). A functional prototype was tested by general practitioners to test clarity of instructions and to improve usability.

\section{Intervention process}

Clinicians were asked to open a web-page when a child presented with a RTI, and login to a website which provided both study information and the intervention. The intervention comprised three active elements: explicit elicitation of parent concerns and expectations (to reduced clinician-perceived pressure to prescribe), the results of a CPR accompanied by delayed or no-antibiotic guidance (to reduce clinical uncertainty), and provision of a personalized printout for carers (to provide an alternate treatment action for clinicians).

Clinicians in the treatment arm were guided through 5 webpages. Pages 1 and 2 required recording of sociodemographic and eligibility criteria, clinical observations and parent reported symptoms (forced questions) which drove the CPR. On page 3 clinicians were asked "Please ask the parent/carer what their worries and expectations are today. Is there anything in particular they wanted to talk about?" and provided with a list of common concerns plus a free text box. If no concerns were recorded an alert appeared to confirm the parent/ carer had no concerns. Page 4 provided the results of the $\mathrm{CPR}$ as numerical relative risk of hospitalization along with antibiotic treatment recommendations, and information about likely illness duration (Fig. 4). Page 4 requested clinicians select their treatment decision from homecare, immediate antibiotic, delayed antibiotic, referral to secondary care, primary care followup appointment (multiple selections permitted). Selection of their treatment option(s), together with clinical signs, symptoms and parent concerns generated a parent-facing leaflet (Fig. 5) which we presented as a print option on page 5 . This leaflet was individualized with the child and clinician's name, date, home care advice responding to symptoms, concerns and treatment selected, and standard safety-netting advice (Additional file 2).

Table 1 Recommendations for interventions to change clinician prescribing behavior

\begin{tabular}{ll}
\hline An intervention to change clinician prescribing behavior SHOULD: & $\begin{array}{l}\text { An intervention to change clinician prescribing } \\
\text { behavior SHOULD NOT: }\end{array}$ \\
\hline $\begin{array}{l}\text { 1. Give explicit antibiotic prescription recommendations } \\
\text { 2. Give alternative treatment options (including for parents e.g. home care advice, and } \\
\text { clinicians e.g. delayed scripts) }\end{array}$ & $\begin{array}{l}\text { 1. Work against the environment in which clinician } \\
\text { operates (e.g. in conflict with targets) } \\
\text { 2. Be generic }\end{array}$ \\
$\begin{array}{l}\text { 3. Address the treatment/no treatment distinction made by clinicians } \\
\text { 4. Give information on specific symptoms }\end{array}$ & $\begin{array}{l}\text { 3. Patronize or undermine parental or clinician } \\
\text { decision making }\end{array}$ \\
$\begin{array}{l}\text { 5. Should address both clinicians AND parents (though we don't know if there is a } \\
\text { difference if they receive information together) }\end{array}$ & $\begin{array}{l}\text { 4. Be passive (e.g. posters) } \\
\text { 6. Increase anxiety or perception of risk for either party }\end{array}$ \\
$\begin{array}{l}\text { common and/or stated (not implied) concerns of parents } \\
\text { 7. Address known environmental pressures (e.g. external pressures to prescribe/consult) }\end{array}$ & \\
$\begin{array}{l}\text { 8. Should make clinicians feel more confident/experienced } \\
\text { 9. Acknowledge treatment decisions in care of childhood RTls are usually made in the } \\
\text { absence of definitive diagnosis. Novel methods to reduce uncertainty may be helpful. }\end{array}$ & \\
10. Be designed in consultation with clinicians and parents & \\
\hline
\end{tabular}




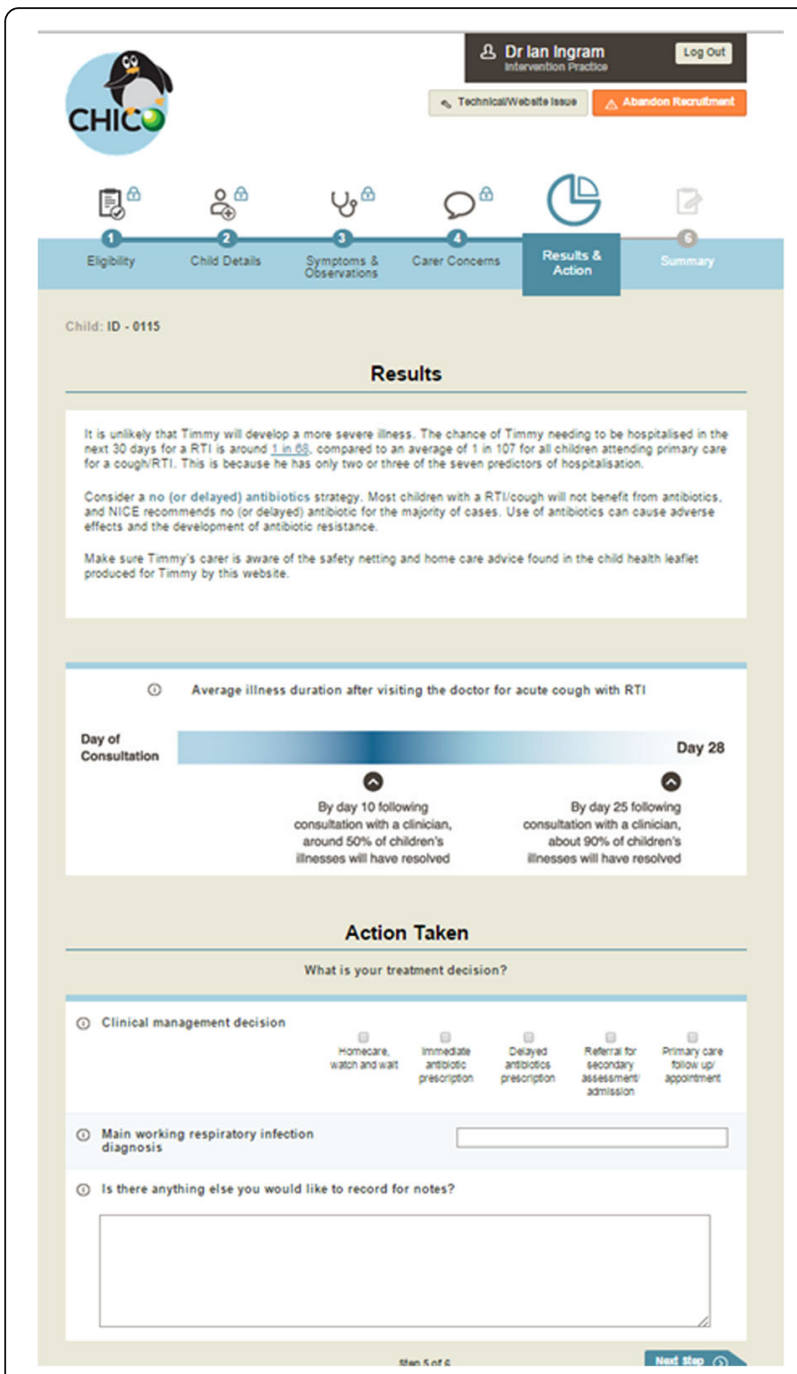

Fig. 4 Example Clinical Prediction Rule and Prescription Guidance Results Screen

\section{Testing feasibility}

The results of the feasibility study are published elsewhere [35]. We found the intervention components themselves acceptable and the parent leaflet highly appreciated by some clinicians. However, the use of a stand-alone website that required login was a barrier to use.

\section{Discussion}

\section{Summary}

We successfully used the Precede/Proceed to structure a synthesis of the findings from a programme of study to inform a complex intervention. We concluded that interventions which reduce clinical uncertainty, reduce clinician/parent miscommunication, make clear delayed/ no-antibiotic recommendations, and provide clinicians with alternate treatment actions have the best chance of

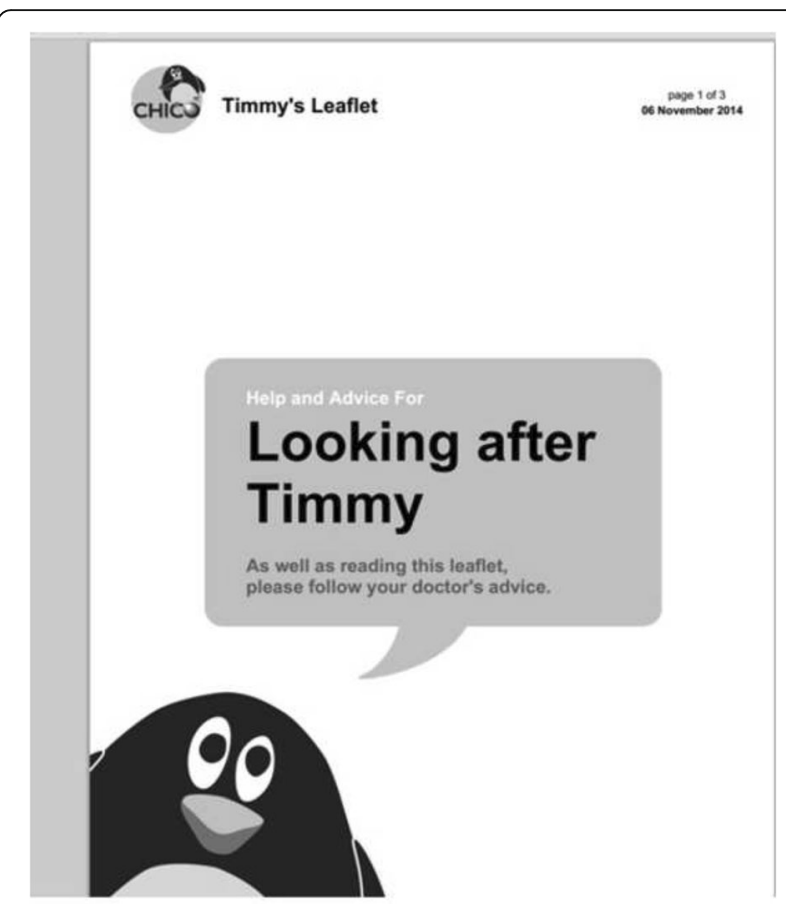

Fig. 5 Example of Individualized Parent-facing Leaflet

reducing antibiotic prescriptions in primary care for childhood RTI.

Our synthesis provides a method for the development of future complex interventions in primary care using a theoretical framework combined with empirical findings. This publication makes explicit the steps we undertook in intervention design prior to piloting, and enables examination of any changes we might make to the intervention design between feasibility and effectiveness studies [19].

\section{Strengths and weaknesses of our approach}

The strength of our approach was to allow strength of evidence to be considered within theoretically driven logic model development. We integrated quantitative and qualitative findings to develop an evidence-based model that reflected the experiences and views of parents and clinicians. We produced generalizable intervention recommendations, as well as the intervention developed for this context. This was possible because of the context of a National Institute for Health Research programme grant, enabling the same group of researchers to work together across phases of intervention development [15], and working in an interdisciplinary team in a multi-method environment. We therefore see our funding context are a key element in our success.

The weakness of this approach was in moving from intervention recommendations, to decisions about how to implement these in practice. While we were confident about the principles guiding intervention development, 
we had to rely on expert opinion and traditional testing with users to inform the many practical decisions involved in designing the intervention. The effectiveness of web-based interventions varies greatly [59] and very little is known at present about the mechanisms through which interventions work. Limited systematic research had been conducted to identify the design features most likely to result in behavioural change [60,61].

An advantage of the Precede/Proceed framework includes consideration of actions to change social norms, regulatory constraints, resource availability. However, our application of it was limited by the research evidence available concerning childhood RTIs. Within both the primary data we generated and the systematic reviews we undertook in our TARGET programme, there was a focus on drivers of prescribing within the patient consultation. The decision aids and clinician communication tools that act within consultations sit within a broader range of interventions which act to change the context for consultations. Recent evidence for population-level changes suggests that shifting social norms through mass communication [62] and prescriber feedback [63] can influence antibiotic prescribing behaviour.

We underestimated the barriers to use of a standalone website, and were not able to integrate this intervention into existing electronic medical notes systems.

\section{Comparison to similar literature}

Interventions informed by evidence and theory have the best chance of altering health related behaviours [15]. However, methods and advice for how to achieve this to develop a specific intervention are sparse $[17,64,65]$. We believe our combination of strength of evidence applied to a theoretical structure, augmented with input from key stakeholders provides a useful model to achieve this.

We drew on a developing literature using logic models to inform mixed methods syntheses of research $[66,67]$. Our work complements the contemporaneous work of Yardley and colleagues in developing their 'person-based approach to intervention development' which similarly combines mixed methods primary research with theoretical models [68]. Michie's behaviour change wheel usefully synthesised behaviour change theories to identify key influences on individual behaviours [69]. Our strength of evidence approach adds to this body of work a mechanism for identifying which actions were most likely to elicit change in this case.

Our approach is similar to those employed by O'Brien and colleagues to develop a web-based healthy lifestyles intervention for older adults [65] and Salisbury and colleagues to develop a new telehealth intervention for chronic disease in adults using Precede/Proceed [57]. Both of these studies used systematic reviews of the existing evidence, supplemented with additional primary research and stakeholder consultation [57], or co-design workshops [65]. Both study teams describe the success of this structured approached, and the tele-health intervention has since been tested, with modest benefits for patient health [70]. However, like us, while the evidence review provided functional guidance, authors report little guidance about the design features of the website [65].

Responding to the scale of the AMR challenge, there are very many interventions aimed at reducing antibiotic prescribing for RTIs in primary care, although fewer focus on children specifically. Many combine approaches drawing on previous research to suggest intervention elements. Four recent trials of family practitioner training using previous research to establish effective interventions and combine approaches in a new multicomponent intervention with mixed success [63, 71-73], in one case highlighting differential effects by age where a reduction in prescriptions was seen for adults and adolescents, but not children under 12 [71]. Two studies are ongoing $[74,75]$. These approaches to changing the environment for prescribing and use of social norms including through peers are consistent with our model.

There is a growing literature testing methods to change professionals' behaviour. Prior literature establishes that education alone is insufficient to change prescribing behaviour in primary care [76], although we know that computerised reminders can be effective [77]. Our research contributes to the gap identified in using computerised reminders as part of a more complex decision support system [77], but our intervention would benefit from better integration into electronic health record systems.

\section{Conclusions \\ Implications for research}

Using the Precede/Proceed model successfully enabled the integration of multiple studies into a critical synthesis of evidence to inform development of a complex behaviour change intervention. The intervention benefitted from the inclusion of qualitative research, which provided rich data to support theory generation, interpretation of quantitative findings, and content for the intervention. Quantitative research provided the best available evidence on likely effective actions, and on the natural history of childhood coughs which are common, minor, and burdensome for children, families and health services. This method for developing a model of behavioural change also enabled the identification elements that would be useful in a future process evaluation.

Research into moving from intervention aims and behavioural targets, to advice for intervention design and delivery would be valuable $[17,65]$. For example, 
while our aim to reduce clinical uncertainty was clear, how and when to present the CPR and symptom duration information to achieve this was a matter of opinion. Although we were guided by the views and experiences of clinicians in our team, steering group, and advisory groups, the challenge of presenting scientifically accurate data (with appropriate confidence boundaries) as a reassuring statement was considerable.

We moved outside the evidence we had gathered, and adopted best practice from other studies in producing tailored advice for each child [78]. One of the advantages of web-based health interventions is the increased facility for tailoring and presenting individualized information which may be more engaging, relevant and motivating [79]. While we know that clinicians liked this feature, we do not yet know which elements and in what circumstance such tailoring makes a difference.

Making explicit the methods for intervention development is an important step in improving transparency in intervention design and testing. This publication demonstrates one approach to this, and will allow examination of future changes to our intervention.

\section{Implications for practice}

Our model suggests actions that can be taken by individual clinicians and medical practices to reduce their use of antibiotics. These include creating an environment where non-use of antibiotics is viewed positively, including considering how to stop 'no-treatment' decisions feeling like a non-action decision for clinicians; ensuring parents know how to recognise 'abnormal' symptoms and (conversely) what is expected when a child is ill; and discouraging clinicians from using the language of serious/minor illness to describe treatable/non-treatable cases. These actions should reduce pressures to prescribe within consultations. We have developed one particular intervention responding to these within-consultation factors. But other solutions, including at population, regulatory and policy level, are consistent with our model and could be usefully tested in practice.

\section{Additional files}

Additional file 1: TIDieR Checklist. (DOCX $29 \mathrm{~kb})$

Additional file 2: Responsive Safety Netting Advice. (DOCX 23 kb)

\section{Abbreviations}

AMR: Antimicrobial resistance; CPR: Clinical prediction rule; RCT: randomised controlled trial; RTI: Respiratory tract infections; SR: Systematic review; WS: Workstream

\section{Acknowledgments}

The authors are extremely grateful to the children, parents/carers and families who have participated in these studies, all GP practices including recruiting clinicians, administrative and research contacts and all other staff whose participation made the TARGET programme possible. We thank colleagues from the TARGET Programme, the TARGET Programme Management Group and the TARGET Programme Steering Committee and our parent and clinician advisory groups for their time, expertise and support.

\section{Funding}

The TARGET Programme is funded by the National Institute for Health Research's Programme Grant for Applied Research Programme. This paper presents independent research funded by the National Institute for Health Research (NIHR) under its Programme Grant for Applied Research (Grant Reference Number RP-PG-0608-10,018). The views expressed are those of the author(s) and not necessarily those of the NHS, the NIHR or the Department of Health. The NIHR had no role in the design of the study, nor in the collection, analysis, and interpretation of data, nor in writing the manuscript. NMR's time is supported by the National Institute for Health Research (NIHR) Collaboration for Leadership in Applied Health Research and Care West (CLAHRC West) at University Hospitals Bristol NHS Foundation Trust.

\section{Availability of data and materials}

The datasets generated and/or analysed during the current study are not publicly available in accordance with our consenting procedures and to protect patient and clinician anonymity but are available from the programme principal investigator Alastair.Hay@bristol.ac.uk on reasonable request and with the permission of the programme management group.

\section{Authors' contributions}

All authors contributed to the TARGET programme activities of which $\mathrm{AH}$ is the guarantor; PJL, JI \& NMR were responsible for developing the research question and study design for this synthesis; PJL, NMR \& J were responsible for study management; all authors contributed to discussion and development of the model; PJL, JI, NMR, CC, ST and AH all contributed to the writing of the manuscript; PJL accepted the final version and is manuscript guarantor. All authors read and approved the final manuscript.

\section{Ethics approval and consent to participate}

Ethical approval was obtained for all included studies. The cohort study was approved by the South West Central Bristol Research Ethics Committee, UK (reference number: 10/H0102/54) and research governance approvals obtained across all areas prior to the start of recruitment in those areas. Approval for qualitative research was obtained from the NHS Ethics Committee South West 4 (ref. 10/H0102/55). All participants (or parents and guardians of those under 16) provided informed written consent.

\section{Consent for publication}

Not applicable.

\section{Competing interests}

The authors declare that they have no competing interests in this section.

\section{Publisher's Note}

Springer Nature remains neutral with regard to jurisdictional claims in published maps and institutional affiliations.

\section{Author details}

${ }^{1}$ School for Policy Studies, University of Bristol, 8 Priory Rd, Bristol, UK. ${ }^{2}$ Centre for Child and Adolescent Health, Population Health Sciences, Bristol Medical School, University of Bristol, Bristol, UK. ${ }^{3}$ National Institute for Health Research Collaborations for Leadership in Applied Health Research and Care West (NIHR CLAHRC West), University Hospitals Bristol NHS Foundation Trust, Bristol, UK. ${ }^{4}$ Centre for Academic Primary Care, Population Health Sciences, Bristol Medical School, University of Bristol, Bristol, UK.

Received: 24 May 2017 Accepted: 6 December 2017

Published online: 28 December 2017

\section{References}

1. WHO: WHO Global Strategy for Containment of Antimicrobial Resistance. In. Geneva: World Health Organisation; 2001.

2. The White House: National strategy for combating antibioticresistant bacteria In. Washington DC, USA: The White House; 2014. 
3. Department of Health: UK Five Year Antimicrobial Resistance Strategy 2013 to 2018. In. Edited by Deapartment of Health DotEaRA, Northern Ireland Executive, Welsh Government, The Scottish Government London, UK: Department of Health; 2013.

4. Ardal C, Outterson K, Hoffman SJ, Ghafur A, Sharland M, Ranganathan N, Smith R, Zorzet A, Cohn J, Pittet D, et al. International cooperation to improve access to and sustain effectiveness of antimicrobials. Lancet. 2016;387(10015):296-307.

5. Shallcross LJ, Howard SJ, Fowler T, Davies SC. Tackling the threat of antimicrobial resistance: from policy to sustainable action. Philos Trans $\mathrm{R}$ Soc Lond Ser B Biol Sci. 2015;370(1670):20140082.

6. Drekonja D, Filice G, Greer N, Olson A, MacDonald R, Rutks I, Wilt TJ. VA evidence-based synthesis program reports. In: Antimicrobial Stewardship Programs in Outpatient Settings: A Systematic Review. Department of Veterans Affairs: Washington (DC); 2014

7. Dar OA, Hasan R, Schlundt J, Harbarth S, Caleo G, Dar FK, Littmann J, Rweyemamu M, Buckley EJ, Shahid M, et al. Exploring the evidence-base for national and regional policy interventions to combat resistance. Lancet. 2016:387(10015):285-95.

8. Gould IM, Lawes T. Antibiotic stewardship: prescribing social norms. Lancet (London, England). 2016;387(10029):1699-701.

9. Tannen D, Wallat C. Interactive frames and knowledge schemas in interaction: examples from a medical examination/interview. Soc Psychol Q. 1987;50(2):205-16.

10. Tates K, Meeuwesen L. Let mum have her say': turntaking in doctor-parentchild communication. Patient Educ Couns. 2000;40(2):151-62.

11. Stivers T, Mangione-Smith R, Elliott MN, McDonald L, Heritage J. Why do physicians think parents expect antibiotics? What parents report vs what physicians believe. J Fam Pract. 2003;52(2):140-8.

12. Mangione-Smith R, McGlynn EA, Elliott MN, McDonald L, Franz CE, Kravitz RL. Parent expectations for antibiotics, physician-parent communication, and satisfaction. Archives of Pediatrics \& Adolescent Medicine. 2001;155(7):800-6.

13. Cahill P, Papageorgiou A. Video analysis of communication in paediatric consultations in primary care. Br J Gen Pract. 2007;57:866-71.

14. Hay AD, Heron J, Ness A. The prevalence of symptoms and consultations in pre-school children in the Avon longitudinal study of parents and children (ALSPAC): a prospective cohort study. Fam Pract. 2005;22(4):367-74

15. MRC: Developing and evaluating complex interventions: new guidance. In. London: Medical Research Council; 2008.

16. Aventin A, Lohan M, O'Halloran P, Henderson M. Design and development of a film-based intervention about teenage men and unintended pregnancy: applying the Medical Research Council framework in practice. Evaluation and program planning. 2015;49c:19-30.

17. Wight $D$, Wimbush $E$, Jepson $R$, Doi L. Six steps in quality intervention development (6SQulD). J Epidemiol Community Health. 2015:1-6.

18. Hoffmann TC, Glasziou PP, Boutron I, Milne R, Perera R, Moher D, Altman DG, Barbour V, Macdonald $H$, Johnston $M$, et al. Better reporting of interventions: template for intervention description and replication (TIDieR) checklist and guide. BMJ (Clinical research ed). 2014;348:g1687.

19. Colquhoun HL, Squires JE, Kolehmainen N, Fraser C, Grimshaw JM. Methods for designing interventions to change healthcare professionals' behaviour: a systematic review. Implementation science : IS. 2017;12(1):30.

20. Andrews T, Thompson M, Buckley DI, Heneghan C, Deyo R, Redmond N, Lucas P, Blair P, Hay AD. Interventions to influence consulting and antibiotic use for acute respiratory tract infections in children: a systematic review and meta-analysis. PLoS One. 2012;7(1):e30334.

21. Ingram J, Cabral C, Hay AD, Lucas P, Horwood J. Parents' information needs, self-efficacy and influences on consulting for childhood respiratory tract infections: a qualitative study. BMC Fam Pract. 2013;14:106.

22. Redmond NM, Davies R, Christensen H, Blair PS, Lovering AM, Leeming JP, Muir $\mathrm{P}$, Vipond B, Thornton $\mathrm{H}$, Fletcher $\mathrm{M}$, et al. The TARGET cohort study protocol: a prospective primary care cohort study to derive and validate a clinical prediction rule to improve the targeting of antibiotics in children with respiratory tract illnesses. BMC Health Serv Res. 2013;13:322.

23. Thompson M, Vodicka TA, Blair PS, Buckley DI, Heneghan C, Hay AD, Team TP. Duration of symptoms of respiratory tract infections in children: systematic review. BMJ. 2013;347:f7027.

24. Vodicka TA, Thompson M, Lucas P, Heneghan C, Blair PS, Buckley DI, Redmond N, Hay AD. Team TP: reducing antibiotic prescribing for children with respiratory tract infections in primary care: a systematic review. The British journal of general practice : the journal of the Royal College of General Practitioners. 2013;63(612):e445-54.

25. Cabral C, Horwood J, Hay AD, Lucas PJ. How communication affects prescription decisions in consultations for acute illness in children: a systematic review and meta-ethnography. BMC Fam Pract. 2014;15:63.

26. Cabral C, Ingram J, Hay AD, Horwood J. "They just say everything's a virus" parent's judgment of the credibility of clinician communication in primary care consultations for respiratory tract infections in children: a qualitative study. Patient Educ Couns. 2014;95(2):248-53.

27. Cabral C, Lucas PJ, Ingram J, Hay AD, Horwood J. "It's safer to ..." parent consulting and clinician antibiotic prescribing decisions for children with respiratory tract infections: An analysis across four qualitative studies. Social science \& medicine. 2015;136-137C:156-64.

28. Lucas PJ, Cabral C, Hay AD, Horwood J. A systematic review of parent and clinician views and perceptions that influence prescribing decisions in relation to acute childhood infections in primary care. Scand J Prim Health Care. 2015:1-10

29. Turnbull SL, Redmond NM, Lucas P, Cabral C, Ingram J, Hollinghurst S, Hay AD, Peters TJ, Horwood J, Little P, et al. The CHICO (Children's Cough) Trial protocol: a feasibility randomised controlled trial investigating the clinical and cost-effectiveness of a complex intervention to improve the management of children presenting to primary care with acute respiratory tract infection. 2015;5(9):e008615.

30. Hay AD, Redmond NM, Turnbull S, Christensen $\mathrm{H}$, Thornton $\mathrm{H}$, et al. Development and internal validation of a clinical rule to improve antibiotic use in children presenting to primary care with acute respiratory tract infection and cough: the 'TARGET' prognostic cohort study. Lancet Respiratory Medicine. 4(11):902-10. doi:10.1016/S2213-2600(16)30223-5. Epub 2016 Sept 1

31. Horwood J, Cabral C, Hay AD, Ingram J. Primary care clinician antibiotic prescribing decisions in consultations for children with RTIs: a qualitative interview study. Br J Gen Pract. 2016;66(644):e207-13.

32. Hay AD, Redmond NM, Turnbull S, Christensen $H$, Thornton $H$, Little $P$, Thompson M, Delaney B, Lovering AM, Muir P, et al. Development and internal validation of a clinical rule to improve antibiotic use in children presenting to primary care with acute respiratory tract infection and cough: a prognostic cohort study. The Lancet Respiratory Medicine. 4(11):902-10.

33. Michie S. Designing and implementing behaviour change interventions to improve population health. Journal of Health Services Research \& Policy. 2008;13(3):64-9.

34. Michie S, Abraham C. Interventions to change health behaviours: evidencebased or evidence-inspired? Psychol Health. 2004;19(1):29-49.

35. Blair PS, Turnbull S, Ingram JC, Redmond NM, Lucas PJ, Cabral C, Hollinghurst S, Dixon P, Peters TJ, Horwood J, Little P, Francis N, Gilbertson A, Jameson C, Hay AD. Feasibility cluster randomised controlled trial of a within-consultation intervention to reduce antibiotic prescribing for children presenting to primary care with acute respiratory tract infection and cough. BMJ Open. 2017:7(5):e014506. doi:10.1136/bmjopen-2016-014506.

36. Hay AD, Redmond NM, Turnbull S, Christensen $H$, Thornton $H$, Little $P$, Thompson M, Delaney B, Lovering AM, Muir $\mathrm{P}$, et al. Development and internal validation of a clinical rule to improve antibiotic use in children presenting to primary care with acute respiratory tract infection and cough: a prognostic cohort study. Lancet Respir Med. 2016.

37. Cabral C, Horwood J, Hay AD, Lucas P. Decision making in consultations for RTI in children: a systematic review and meta-ethnographic synthesis of qualitative data. In: Society for Academic Primary Care Annual Conference: Glasgow: Society for Academic Primary Care; 2012.

38. Lucas PJ, Cabral C, Hay AD, Horwood J. A systematic review of parent and clinician views and perceptions that influence prescribing decisions in relation to acute childhood infections in primary care. Scand J Prim Health Care. 2015;33(1):11-20.

39. Cabral C, Ingram J, Hay AD, Horwood J. "They just say everything's a virus" - parent's judgment of the credibility of clinician communication in primary care consultations for respiratory tract infections in children: a qualitative study. Patient Educ Couns. 2014;95(2):248-53.

40. Ingram J, Cabral C, Hay AD, Lucas PJ, Horwood J. Parents' information needs, self-efficacy and influences on consulting for childhood respiratory tract infections: a qualitative study. BMC Fam Pract. 2013;14:106.

41. Green LW, Kreuter M. Health program planning: an educational and ecological approach. New York: McGraw-Hill; 2005. 
42. The Precede-Proceed Model of Health Program Planning \& Evaluation. http://green.net/precede.htm.

43. Abraham C, Michie S. A taxonomy of behavior change techniques used in interventions: Health Psychology. 2008;27(3):379-87.

44. Weinstein ND. Testing four competing theories of health-protective behavior. Health Psychology. 1993;12(4):324-33.

45. Conner M, Norman P. Predicting health behaviour. Maidenhead: Open University Press; 2005.

46. de Vlaming R, Haveman-Nies A, Van't veer P, de Groot LC. Evaluation design for a complex intervention program targeting loneliness in noninstitutionalized elderly Dutch people. BMC Public Health. 2010;10:552.

47. Dykeman M, Maclntosh J, Seaman P, Davidson P. Development of a program logic model to measure the processes and outcomes of a nursemanaged community health clinic. J Prof Nurs. 2003;19(4):197-203.

48. Fielden SJ, Rusch ML, Masinda MT, Sands J, Frankish J, Evoy B. Key considerations for logic model development in research partnerships: a Canadian case study. Evaluation \& Program Planning. 2007:30(2):115-24.

49. Gugiu PC, Rodriguez-Campos L. Semi-structured interview protocol for constructing logic models. Evaluation \& Program Planning. 2007;30(4):339-50

50. Helitzer D, Hollis C, de Hernandez BU, Sanders M, Roybal S, Van Deusen I. Evaluation for community-based programs: the integration of logic models and factor analysis. Evaluation \& Program Planning. 2010;33(3):223-33.

51. Huberty JL, Balluff M, O'Dell M, Peterson K. From good ideas to actions: a model-driven community collaborative to prevent childhood obesity. Prev Med. 2010;50(Suppl 1):S36-43.

52. Langlois MA, Hallam JS. Integrating multiple health behavior theories into program planning: the PER worksheet. Health Promot Pract. 2010;11(2):282-8.

53. Medeiros LC, Butkus SN, Chipman H, Cox RH, Jones L, Little D. A logic model framework for community nutrition education. Journal of Nutrition Education \& Behavior. 2005;37(4):197-202.

54. Toumbourou JW, Bamberg JH. Family recovery from youth substance use related problems: a pilot study of the BEST plus program. Substance Use \& Misuse. 2008;43(12-13):1829-43.

55. Larson EL, Dilone J, Marcia M, Smolowitz J. Factors which influence Latino community members to self-prescribe antibiotics. Nurs Res. 2006:55(2):94-102.

56. Yardley L, Miller S, Teasdale E, Little P. On behalf of the Primit team: using mixed methods to design a web-based Behavioural intervention to reduce transmission of colds and flu. J Health Psychol. 2011;16(2):353-64.

57. Salisbury C, Thomas C, O'Cathain A, Rogers A, Pope C, Yardley L, Hollinghurst S, Fahey T, Lewis G, Large S, et al. TElehealth in CHronic disease: mixed-methods study to develop the TECH conceptual model for intervention design and evaluation. BMJ Open. 2015;5(2):e006448.

58. NICE. Respiratory tract infections - antibiotic prescribing prescribing of antibiotics for self-limiting respiratory tract infections in adults and children in primary care. In: NICE clinical guideline 69. London: National Institute for Health and Clinical Excellence; 2008.

59. Bennett $\mathrm{G}$, Glasgow R. The delivery of public health interventions via the Internet: Actualising their potential. Annual Review of Public Health. 2009;30:273-92.

60. Morrison L, Yardley L, Powell J, Michie S. What design features are used in effective e-health interventions? A review using techniques from critical interpretive synthesis. Telemedicine and e-Health Telemed J E Health. 2012;18(2):137-44.

61. Edwards J, Charani E, Sevdalis N, Alexandrou B, Sibley E, Mullett D, Loveday H, Drumright L, Holmes A, Edwards R, Charani E, Sevdalis N, Alexandrou B,

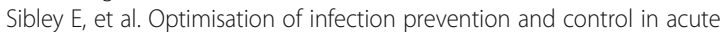
health care by use of behaviour change: a systematic review. Lancet Infect Dis. 2012:12(4):318-29.

62. Cross EL, Tolfree R, Kipping R. Systematic review of public-targeted communication interventions to improve antibiotic use. J Antimicrob Chemother. 2017;72(4):975-87.

63. Hallsworth M, Chadborn T, Sallis A, Sanders M, Berry D, Greaves F, Clements $L$, Davies SC. Provision of social norm feedback to high prescribers of antibiotics in general practice: a pragmatic national randomised controlled trial. Lancet (London, England). 2016;387(10029):1743-52.

64. De Silva MJ, Breuer E, Lee L, Asher L, Chowdhary N, Lund C, Patel V. Theory of change: a theory-driven approach to enhance the Medical Research Council's framework for complex interventions. Trials. 2014;15:267.

65. O'Brien N, Heaven B, Teal G, Evans EH, Cleland C, Moffatt S, Sniehotta FF, White M, Mathers JC, Moynihan P. Integrating evidence from systematic reviews, qualitative research, and expert knowledge using co-design techniques to develop a web-based intervention for people in the retirement transition. J Med Internet Res. 2016;18(8):e210.

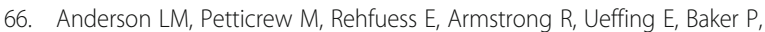
Francis D, Tugwell P. Using logic models to capture complexity in systematic reviews. Research synthesis methods. 2011;2(1):33-42.

67. Johnson MJ, May CR. Promoting professional behaviour change in healthcare: what interventions work, and why? A theory-led overview of systematic reviews. BMJ Open. 2015;5(9):e008592.

68. Yardley L, Morrison L, Bradbury K, Muller I. The person-based approach to intervention development: application to digital health-related behavior change interventions. J Med Internet Res. 2015;17(1):e30.

69. Michie S, van Stralen MM, West R. The behaviour change wheel: a new method for characterising and designing behaviour change interventions. Implement Sci. 2011;6(1):42.

70. Salisbury C, O'Cathain A, Thomas C, Edwards L, Gaunt D, Dixon P, Hollinghurst S, Nicholl J, Large S, Yardley L, et al. Telehealth for patients at high risk of cardiovascular disease: pragmatic randomised controlled trial. BMJ. 2016:353:i2647.

71. Vervloet M, Meulepas MA, Cals JW, Eimers M, van der Hoek LS, van Dijk L. Reducing antibiotic prescriptions for respiratory tract infections in family practice: results of a cluster randomized controlled trial evaluating a multifaceted peer-group-based intervention. NPJ primary care respiratory medicine. 2016;26:15083.

72. van der Velden AW, Kuyvenhoven MM, Verheij TJ. Improving antibiotic prescribing quality by an intervention embedded in the primary care practice accreditation: the ART14 randomized trial. J Antimicrob Chemother. 2016;71(1):257-63.

73. Hurlimann D, Limacher A, Schabel M, Zanetti G, Berger C, Muhlemann K, Kronenberg A. Improvement of antibiotic prescription in outpatient care: a cluster-randomized intervention study using a sentinel surveillance network of physicians. J Antimicrob Chemother. 2015;70(2):602-8.

74. Juszczyk D, Charlton J, McDermott L, Soames J, Sultana K, Ashworth M, Fox R, Hay AD, Little P, Moore MV, et al. Electronically delivered, multicomponent intervention to reduce unnecessary antibiotic prescribing for respiratory infections in primary care: a cluster randomised trial using electronic health records-REDUCE trial study original protocol. BMJ Open. 2016;6(8):e010892

75. Avent ML, Hansen MP, Gilks C, Del Mar C, Halton K, Sidjabat H, Hall L, Dobson A, Paterson DL, van Driel ML. General practitioner antimicrobial stewardship Programme study (GAPS): protocol for a cluster randomised controlled trial. BMC Fam Pract. 2016;17:48.

76. Guthrie B, Kavanagh K, Robertson C, Barnett K, Treweek S, Petrie D, Ritchie L, Bennie M. Data feedback and behavioural change intervention to improve primary care prescribing safety (EFIPPS): multicentre, three arm, cluster randomised controlled trial. BMJ (Clinical research ed). 2016:354:44079.

77. Grimshaw JM, Eccles MP, Lavis JN, Hill SJ, Squires JE. Knowledge translation of research findings. Implementation science : IS. 2012;7:50.

78. Kreuter MW, Skinner CS. Tailoring: what's in a name? Health Educ Res. 2000; 15(1):1-4.

79. Lustria ML, Cortese J, Noar SM, Glueckauf RL. Computer-tailored health interventions delivered over the web: review and analysis of key components. Patient Educ Couns. 2009;74(2):156-73.

\section{Submit your next manuscript to BioMed Central and we will help you at every step:}

- We accept pre-submission inquiries

- Our selector tool helps you to find the most relevant journal

- We provide round the clock customer support

- Convenient online submission

- Thorough peer review

- Inclusion in PubMed and all major indexing services

- Maximum visibility for your research

Submit your manuscript at www.biomedcentral.com/submit 